\title{
LA SITUACIÓN DE LOS RUNAS EN LA CONCEPCIÓN DE GUAMÁN POMA DE AYALA: iY NO HAY REMEDIO!
}

\author{
THE SITUATION OF THE RUNAS IN THE CONCEPTION OF GUAMAN \\ POMA DE AYALA: \\ AND THERE IS NO REMEDY! \\ (iD) Nelson Paucca Gonzales ${ }^{*}$ \\ npaucca@ipnm.edu.pe \\ ${ }^{1}$ Instituto Pedagógico Nacional Monterrico/Universidad Nacional de Educación \\ *Correspondencia: Nelson Paucca Gonzales. Email: npaucca@ipnm.edu.pe
}

Recibido: 01.10.19 | Aprobado: 01.12.19

\section{RESUMEN}

El artículo se centra en la explicitación de la concepción de Guamán Poma de Ayala, en torno a la interpelación de las quejas respecto al desorden que habían iniciado los invasores españoles en la sociedad incaica. En su escrito, el autor resalta tres aspectos fundamentales: primero, describe la situación desarrollada por los incas antes de la invasión. Segundo, interpela las quejas ante la corona española acerca de los actos inmorales que estaban cometiendo los invasores en contra de los indígenas. A fin de resumir estos hechos el autor acuña la frase "Y NO HAY REMEDIO". Tercero, plantea alternativas de solución a fin de salvaguardar la situación caótica por la que estaba atravesando la sociedad Incaica; además el autor propone al rey de España y a los lectores cristianos asegurar la tranquilidad y mantener la relación armónica entre la corona española y los runas de esta sociedad.

Palabras clave: Runas, la nueva corónica, no hay remedio, lectores cristianos.

\section{ABSTRACT}

The article focuses on the explanation of the conception of Guaman Poma de Ayala, regarding the interpellation of complaints related to the disorder that the Spanish invaders had initiated in Inca society. In his writing, the author highlights three fundamental aspects: first, he describes the situation developed by the Incas before the invasion. Second, he enquires the complaints to the Spanish crown about the immoral acts that the invaders were committing against the natives, in order to summarize these facts the author coined the phrase "AND THERE IS NO REMEDY". Third, it proposes alternative solutions in order to safeguard the chaotic situation that Inca society was going through, and the author proposes to the king of Spain and Christian readers to guarantee tranquility and maintain the harmonious relationship between the Spanish crown and the runes of this society.

Keywords: Runas, the new corónica, no remedy, Christian readers. 


\section{INTRODUCCIÓN}

Felipe Guaman Poma de Ayala, en pleno proceso de la colonia tuvo el atrevimiento de plantear las diferentes quejas a la corona española a través de su obra titulada Nueva Corónica ${ }^{1}$ y Buen Gobierno, con el propósito de salvaguardar la situación caótica por la que estaban atravesando los runas de la sociedad Inca y el orden que habían mantenido los runas $^{2}$ de esta tierra hasta la llegada de los invasores. A través de su obra el autor expresa el sentir de los runas de esta sociedad. Por otra parte, el término Nueva Corónica es usado por el autor para resaltar los aspectos más relevantes y el buen gobierno que ejercía el rey de España en esa tierra. Posterior a esta descripción de enaltecimiento, el autor inicia a poner de manifiesto hechos de buena relación que se había mantenido en esta tierra antes de la llegada de los invasores. Por otra parte, el autor revela su cometido de interpelar las quejas respectos a los hombres que habían llegado de España, dentro de estas quejas también estaba el pedido especial al Rey de España como es la de asumir la gobernabilidad de manera personal en esta tierra, bajo el título Buen Gobierno, el autor relata lo siguiente:

En primera instancia, el autor presenta a los reyes Incas como gobernantes idóneos, durante su permanencia en el cargo. En la misma línea, responsabiliza a los invasores españoles ${ }^{3}$ de haber generado el desorden y el caos dentro de esta sociedad, advierte que; en caso de no intervenir en este hecho de manera oportuna el rey de España, la desgracia se consumará dando fin a las buenas costumbres practicadas por los runas, y la existencia de una sociedad.

En segunda instancia, el autor reconoce al rey de España como uno de los mejores gobernantes de la corona española y distingue que el problema de esta tierra es producto de la acción de los españoles invasores quienes han llegado a esta tierra.

Cabe mencionar que el propósito es resaltar algunos problemas generales abordado por el autor en lo que respecta a la situación de los runas durante el proceso de Colonización en esta tierra, para lo cual se procederá analizar y explicitar de manera exhaustiva algunos pasajes mencionados por el autor, a fin de evidenciar la mansión del término yy no hay remedio! Sin embargo, dentro de esta agonía el autor aún cree encontrar una repuesta adversa al cual denominó como isi hay remedio! Con el cual, plantea una respuesta al enunciado del título ¡Y NO HAY REMEDIO!

\footnotetext{
${ }^{1}$ En el caso del autor pareciera que a propósito ha colocado el término corónica y no crónica como cotidiamente se suele notar, desde mi percepción el autor con el término corónica se está refiriendo al rey de España, un hombre merecedor y digno poseer una corona sobre su cabeza.

${ }^{2}$ En el presente tratado el concepto runa está referido a las personas; tanto varones y mujeres desde el momento que nacen hasta el momento de su muerte.

${ }^{3}$ El término invasores españoles es acuñado por mí, puesto que Guaman Poma de Ayala los llama conquistadores, naturalmente en la actualidad el término conquistador e invasor tienen diferentes connotaciones, por ello conviene utilizar el término invasor en mi caso, a fin de dar cuenta acerca de los actos cometidos por los españoles, $y$, tal como menciona el autor.
} 


\section{NUEVA CORÓNICA Y BUEN GOBIERNO: UNA INTERPRETACIÓN DESDE LA CONCEPCIÓN DE FELIPE GUAMAN POMA DE AYALA ${ }^{4}$.}

\section{Carta de don Martín Guaman Mallqui}

Antes de abordar la carta escrita por don Martín Guaman Mallqui, se hace un breve análisis del título de la obra; Nueva Corónica y Buen Gobierno ${ }^{5}$, es una necesidad explicitar el propósito de la obra, a fin de entender la pretensión del autor respecto a la condición de los runas $^{6}$ antes, durante y después de la invasión, aunque las pretensiones del autor es diverso; sin embargo, cabe resaltar que el discurso dirigido al rey de España tiene la finalidad de expresar la situación caótico por lo que estaba atravesando la sociedad incaica, en tanto a esta situación era una necesidad el pronunciamiento a fin de salvaguardar la condición humana de los runas. Naturalmente, el pronunciamiento del autor se entiende como la defensa de los otros, a pesar del pronunciamiento personal. En los primeros acápites el autor relata los objetivos que tendría con la corana española como ciudadano común, describe detalladamente su descendencia y finalmente evidencia ser descendiente de los grandes reyes del antiguo Perú. En ese sentido el autor revela la carta escrita por su padre:

[...] carta de don Martín Guaman Mallqui de Ayala hijo y nieto de los grandes señores y reyes que fueron antiguamente y capitán general y señor del reino y cápac apo que es príncipe y señor de provincia de los Lucanas[...] (Guaman Poma, 1993, p. 12)

Sería esta uno de los intentos de hacer la defensa de los runas, el suyo y sus descendientes, la intención de la carta emitida por el padre del autor tienen la finalidad de asegurar el bienestar dentro de esta sociedad como desciende de los reyes de este reino, además de asegurar la sucesión de gobernabilidad de sus descendientes. El padre del autor da cuenta acerca del servicio, que había prestado a la corona española, en consecuencia su hijo y demás descendientes serían merecedores del reconocimiento de parte del rey Felipe III, este pedido tiene su fundamento en el desorden que generaron los invasores españoles desde el momento de su llegada. Frente a este hecho al autor propone dos alternativas: primero, sugiere que el rey de España se haga cargo de dirigir el destino de esta sociedad y la otra alternativa que propone es la de otorgar el cargo a Felipe Guaman Poma de Ayala, para que se haga cargo de la conducción de los runas de la sociedad Inca.

\footnotetext{
${ }^{4}$ Dentro de su obra el autor en varias ocasiones hace mención ser "indio ladino", el autor no precisa el significado de ello, la estudiosa en Guaman Poma, Rolena Adorno sostiene que esta afirmación es compleja y no se sabe con exactitud a lo estaría haciendo referencia. Sin embargo, desde mi concepción se auto denomina. Es decir, Guaman Poma de Ayala es el ente articulador entre el rey de España y los indígenas de la sociedad incaica. Por otra parte, cabe mencionar respecto a la fecha de su nacimiento no se sabe con precisión, sin embargo, en su obra: "Afirma que nació en San Cristóbal de Suntuntu, (o Sondondo), y afirmaba tener 80 años cuando finalizó la escritura de su libro (¿1615?) [...]” (Guaman Poma, 1993, p. X). En realidad la fecha exacta de su nacimiento es un misterio, así como el año en que término de redactar su obra, según "Porras Barnechea (1948:10) opinó que Guaman Poma habría escrito la Nueva Corónica antes de 1600, volviendo a copiar el manuscrito envejecido para uniformarlo con el Buen Gobierno, escrito en 1613" citado en (Adorno, 1989, p. 55). Lo que se puede afirmar categóricamente es el lugar de nacimiento, actualmente es el anexo del valle Sondondo lugar donde nació el autor que aún indican la gente de esa comunidad la casa donde pasó algún tiempo, distrito de Cabana Sur, provincia de Lucanas y departamento de Ayacucho.

${ }^{5}$ Haciendo mención al título de la obra Adorno (1989), afirma lo siguiente: “[...] no se concibió como un diario personal, la obra presenta las reflexiones de un andino pensativo sobre las Corrientes políticas y sociales de la colonia durante un período de varias décadas" (p.43).

${ }^{6}$ El término runa está expresado en el idioma kechwa, significa básicamente "humanidad" o hace referencia a las personas; adultas, jóvenes y niños de la sociedad incaica. En el presente ensayo conviene utilizar el término ruana, puesto es uno de los términos que incluye a toda la especie humana desde la concepción del autor como el mío. En la actualidad los runas de las zonas andinas aún solemos utilizar el término runamasiy para referirnos a nuestros compueblanos en su totalidad.
} 
Teniendo como fundamento lo mencionado, el autor dentro de sus quejas muestra intolerancia frente al desorden que ha ido generando los invasores españoles en esta tierra. Por otra parte, hace notar lo que los runas durante mucho tiempo habían practicado el allin kaysay ${ }^{7}$. La propuesta del autor es explícita al mencionar, que estos señores vienen causando deficiencias entre los hombres de esta tierra, además de atentar en contra de los principios encomendados por la corona española. Guaman Poma tiene pleno conocimiento acerca de la actitud de esto personajes, por lo que no duda manifestar que estos hombres no están ni estarán preparados para dirigir una sociedad como es el caso de la sociedad Inca, frente a este hecho el autor propone al rey Felipe III, que se digne en conceder la direccionalidad o la gobernabilidad de esta tierra uno de los suyos, para ello el padre de Felipe Guaman Poma de Ayala describe que él, su hijo y sus nietos son descendientes de los reyes Incas del Perú, además asegura que en caso de otorgar la potestad a su hijo, la situación de los runas mejoraría. También los tributos a la corona española sería de acuerdo a lo que se puede establecer en el nuevo contrato entre el rey de España y Felipe Guaman Poma de Ayala. Para ello, menciona que los invasores españoles quienes se encuentren en estas tierras solo se han preocupado en enriquecerse dejando de lado el contrato firmado inicialmente. Frente a este hecho, el autor describe como un acto desleal ante la corona española y su majestad. Estos hechos son considerados por el autor como un acto inhumano frente a los españoles y los indígenas. Anterior a la llegada de los españoles, estos actos no se habían notado. La organización en la sociedad incaica estaba bien estructurada, tal es así, que los tukuy ricuq ${ }^{8}$ quienes eran elegidos por las autoridades, para cumplir ciertas funciones dentro de la sociedad con eficacia y lealtad a quienes lo designaron.

Es evidente que los runas de esta sociedad son conocedores y arquitectos de su organización, estas mismas expresiones se pueden notar en la parte introductoria del libro; Historia general del Perú tratado por Murúa (2001):

La conquista del Perú por los españoles abrió un camino inmenso de curiosidades. Pese a la magnitud de lo que se había visto en México y Yucatán, admirando el esplendor bárbaro de aquellas civilizaciones, lo incaico los asombró por su orden, su disciplina y sus enormes realizaciones materiales. Dentro del aspecto bárbaro que ofrecía a los ojos del europeo todo lo indígena, el caso peruano mostraba algunos aspectos que recordaban las estructuras civilizaciones del Viejo Mundo. Esta misma severa y jerárquica organización peruana había permitido la conservación oral de gran número de tradiciones y una verdadera historia, [...] (p. 5)

El reconocimiento que hace Murúa, sustenta lo que propone Guaman Poma de Ayala respecto a la organización social desarrollada por los runas de la sociedad Inca, además hace una comparación sostenible en relación al nivel del desarrollo alcanzado por las sociedades de Yucatán en México. También, hace mención el desarrollo que alcanzaron los runas de esta sociedad respecto a las construcciones arquitectónicas y esta

\footnotetext{
${ }^{7} \mathrm{El}$ buen vivir o la buena vida.

${ }^{8}$ El término es una asociación de vocablos kechwas que se traduce de la siguiente manera; tucuy significa "todo" mientras ricuq significa "el que ve, observa o tiene conocimiento", por lo que significaría tucuy ricuq "el que todo lo ve, lo observa o lo sabe”. Los tucuy ricuq, eran los hombres de confianza de los Inkas y tenían la función de representar al Inka en las diferentes comunidades con la finalidad de llevar las diversas inquietudes de los ayllus "familias" hacia el rey Inka o viceversa. Otros autores mencionan que el tucuy ricuq era el ente articulador o mensajero entre los runas de los cuatro suyos y el rey Inka.
} 
podría estar al nivel del mundo europeo de la época clásica del viejo mundo. Es posible que existan ciertas diferencias en el uso de los materiales y las técnicas empleadas en el proceso de construcción ya que cada una de las sociedades han mostrado su propia particularidad unos más que los otros. El dominio del aspecto arquitectónico es asombroso, por el uso de los bloques de piedras y sobre todo el dominio del espacio geográfico tan accidentado que presenta nuestro territorio en general. A pesar de ello, los runas de esta sociedad resolvieron de manera eficiente las situaciones adversas propias de la época. Guaman Poma de Ayala, no claudica en remitir sus quejas directamente al rey de la corona española además de los lectores cristianos. El autor en primer, lugar considera al rey Felipe III como uno de los personajes más destacados y dignos de una realeza. En ese sentido, el rey sería un individuo con las mismas condiciones y características que Guaman Poma de Ayala, por lo que no existiría ninguna diferencia entre el rey de España y Guaman Poma, además resalta que esta tierra es de los reyes Incas, y los que conocen la organización de esta tierra son los indígenas especialmente los descendientes de los reyes Incas, tal como sostiene don Martín Guaman Mallqui:

[...]. Deseando que todo esta se consiga humildemente suplico a vuestra majestad sea servido de favorecer y hacer merced al dicho mi hijo don Felipe de Ayala y para todo mis nietos para que su pretensión vaya adelante que es lo que pretendo de que a vuestra majestad[...] (Guaman Poma, 1993, p. 13)

El propósito de la carta del padre de Guaman Poma, es hacer un pedido especial para que el rey Felipe III considere a su hijo y sus nietos como herederos con facultades para asumir cargos de funcionario, para el caso de Guaman Poma pide explícitamente que se le otorgue el rango de rey, recordemos que Guaman Poma se declara como rey de esta de esta tierra, en cuanto sea ratificado por el rey de España asumiría el cargo de gobernador dentro de la sociedad Inca, esta propuesta es ratificado por don Martín, en la carta declara que Felipe Guaman Poma es hijo legítimo, por tanto príncipe y gobernador mayor de los runas y demás caciques de la provincia de Lucanas, lugar al que pertenecería su etnia. El pedido hecha por don Martín debía ser concedido por el rey de España, puesto que Guaman Poma de Ayala hace veinte años había escrito la historia de sus antepasados. Naturalmente el autor recién emitiría al rey de España después de veinte cinco años. En la carta muestra temor tanto el padre y el mismo autor ante su majestad y a la corona española. A pesar de los aspectos negativos encontrados en su vida diaria Felipe Guaman Poma de Ayala toma la decisión de poner sus quejas ante de los ojos del rey y lectores cristianos de España, a fin de encontrar soluciones frente a sus quejas, al cual denominaré como una posible respuesta a la exclamación del autor ¡Y NO HAY REMEDIO! Como ¡SI HAY REMEDIO! Siempre en cuando el rey de España le otorgue facultades de rey en esta tierra o en caso de asumir el cargo el propio rey Felipe III de España en esta sociedad. En caso de obtener cualquiera de estas repuestas de manera positiva, el autor comprobaría la frase ¡SI HAY REMEDIO! y se pondría fin a la crisis ocasionado por los invasores españoles y la desarticulación entre los runas de la sociedad incaica y el rey de España. 
Carta de don Felipe Guaman Poma de Ayala a su majestad el rey Felipe III de España

Después de haber examinado la carta emitida por don Martín Guaman Mallqui, conviene analizar la carta escrita por don Felipe Guaman Poma de Ayala al rey Felipe III de España. En principio el autor manifiesta un acto temerario ante el rey de España tal como se puede notar a continuación:

Muchas veces dudé sacra católica real magestad (sic) aceptar esta dicha empresa y muchas más, después de haberla comenzado no quise volver atrás juzgando por temeraria mi intensión, no ballando sujeto en mi facultad para acabarla conforme a la que se debia a unas historias sin escrituras ninguna no más de por los quipos y memorias y relaciones de los indios antiguos de muy viejos y viejas, sabios testigos[...] (Guaman Poma, 1993, pp. 13, 14)

Es posible aceptar la posición temerosa del autor ante su majestad el rey de España y los lectores cristianos, para ello se debe tener en cuenta el contexto y la realidad social por la estaban atravesando los runas de la sociedad Inca y las circunstancias en la que fue escrito y enviado al rey y lectores cristianos de España. Es natural el sentir del autor y la toma de decisión para relatar los actos insólitos cometidos por los invasores españoles en estas tierras, las mismas que no podían ser probados por la distancia entre el autor y el rey de España. Sin embargo, el autor para evidenciar los relatos se vale de los diversos dibujos las mismas que acompañan al escrito de la obra, cada uno de los dibujos están enumeradas y acompañadas de una breve descripción en forma de títulos. La actitud temeraria que muestra el autor debe ser porque antes de la invasión la sociedad Inca no era poseedor de una escritura de tipo gramatical, con ello no estoy sustentando que los runas de la sociedad Inca no eran poseedores de conocimientos, simplemente estoy haciendo referencia a la ausencia de la escritura fonética, lo cual no era del interés de los runas y habían desarrollado otras formas de conservar y registrar los conocimientos. Se debe resaltar que las diferentes informaciones están registrados en los quipos o Kipus $^{9}$ y los únicos responsables de registrar, conservar e interpretar eran los kipukamayoq ${ }^{10}$.

El autor también resalta la función de los viejos sabios a quien se les asigna el nombre de filósofos: “[...] y de otros beneficios que se hacen entendían los filósofos y astrólogos indios; y de ello hasta hoy los entienden los viejos y los mozos que no saben leer ni escribir y pasan por ello los indios" (Guaman Poma, 1993, p. 58). El uso del término filósofo por parte del autor es a fin de hacer notar la sabiduría que poseían los runas de esta sociedad, en el siguiente parágrafo se puede notar la semejanza que existe entre la sabiduría de los runas y de los filósofos como Aristóteles entre otros.

En el idioma kechwa, filósofos recibe la denominación camasca amauta runa ${ }^{11}$, tal como notaremos: "De cómo los dichos filósofos antiguos, que ellos le llamaban camasca

\footnotetext{
${ }^{9}$ Es un término quechua o kechwa que significa "nudo - información" cada uno de estos nudos conservaban informaciones inéditas y de suma relevancia, digo que es inédito puesto que la información solo era proporcionado al rey Inca y la gente de la clase común no tenían acceso a ello.

${ }^{10}$ Los kipukamayoq es un término kechwa compuesta por las siguientes palabras; kipu que significa "nudo - información" y kamayoq que significa "individuo poseedor o el que tiene", en tal sentido kipukamayoq significa individuo poseedor de información.

${ }^{11}$ Conviene traducir literalmente lo propuesto por Guaman Poma; camasca amauta runa. En ese sentido camasca significa "poseedor", amauta significa "sabio, quien enseña o profesor" y runa significa "persona u hombre". Por lo que camasca amauta runa significaría "hombre sabio poseedor de conocimiento", en cuanto poseedor de conocimiento su función era impartir su sabiduría con los runas de la alta élite, para que esta sea entendida oportunamente y predecir los acontecimientos futuras. Se
} 
amauta runa, entendían por las estrella y cometas y del eclipse del sol y de la luna, y de tempestades y de aires y de animales y de pájaros, [...]" (Guaman Poma, 1993, p. 58). Desde mi perspectiva no tiene sentido llamarlo filósofo a los grandes sabios de la sociedad Inca, el término filosofo fácilmente puede ser expresado en el idioma kechwa yachaq runa el cual significa "hombres sabios". Sin embargo, se había manifestado en los acápites anteriores que el autor hace esta mención con la finalidad de dar cuenta en torno a la sabiduría desarrollada por los runas y resaltar las características y fortalezas de los yachaq runas. Debía usar necesariamente el término filósofo para que el rey y los lectores españoles puedan entender la condición de los runas de la sociedad Inca. El atrevimiento y la explicitación del autor, sin duda es de suma importancia, puesto que describe la situación de cómo se encontraba la sociedad antes de la llegada de los invasores, y los hechos que cometen los invasores en estas tierra desde el momento de su llegada hasta los días que termina de registrar en su obra Guaman Poma de Ayala y una tercera propuesta es el planteamiento de las posibles soluciones a fin de salvaguardar el bienestar de todo una sociedad.

\section{Breve aproximación al contenido de la obra de Felipe Guaman Poma de Ayala}

En los siguientes acápites de la obra el autor se ocupa de la descripción del origen de los runas de la sociedad Inca, el ejercicio que cumplieron los reyes como gobernadores en torno a los aspectos políticos, sociales y económicos antes de la llegada de los invasores. Para el autor, es importante la explicitación acerca del proceso evolutivo de los runas de esta tierra, por lo que iniciará haciendo mención a los Uari uiracocha runa, Uari runa, Purun runa, Auca runa y finalmente los Inca runas, cabe mencionar que cada etapa del proceso evolutivo de los runas guardan relación con la práctica del bien, es decir, con la práctica de la verdadera justicia:

[...], por mandato del rey de aquel tiempo; y a los mozos y los niños los doctrinaban y les enseñaba con castigo, como el catón de Roma, que daban buenos ejemplos y enseñaban a sus hijos para que fuesen bien criados. [...] (Ob. Cit. p. 56)

La práctica moral de los runas tenían sus bases en el proceso de la buena enseñanza a base de ejemplos, dichas prácticas debían ser reforzados constantemente desde su infancia con buen ejemplo y buena justicia, además estas prácticas estaban normados y cumplían cabalmente, quizá cabe preguntarse ¿De qué manera se daban las normas si el autor manifiesta que los Inca runas no eran poseedores de letras? Naturalmente la buena práctica del bien no dependía de las letras sino más bien de la práctica misma, por tanto, no era necesario dictaminar normas ni leyes, se entiende que los runas de esta sociedad habían desarrollado el proceso de la comunicación oral además de las formas simbólicas que les servía a los jefes de los ayllus para verificar su cumplimiento. La necesidad de estos esbozos acerca de la situación de los runas en la concepción de Guaman Poma, es a fin de confrontar la crisis que estamos atravesando actualmente, cómo es que las organizaciones delincuenciales y grupos minoritarios están pretendiendo imponer violencia y temor a través de sus actos a una sociedad altamente civilizada y cumplidor de las normas o es que 
los normativistas han quedado solo en interpretaciones. Estos hechos conduce a reformular acerca de la situación por lo que estamos atravesando. Por otra parte, es evidente de que algo está fallando dentro del sistema gubernamental, en ese sentido cabe ensayar algunas preguntas; será que las autoridades no están cumpliendo con sus funciones o es que los padres de familia no cumplen con sus responsabilidades o tal vez los educadores no están enfatizando los problemas de la realidad.

Después de estas reflexiones es necesario también analizar el contenido de la siguiente cita:

De cómo en aquel tiempo no se mataban ni se robaban, ni se echaban maldiciones, ni había adúltera ni ofensa en servicio de Dios, ni había lujuria, envidia, avaricia, gula, soberbia, ira, acidia, pereza, y no había deudas ni mentiras, sino todo $\operatorname{verdad}[\ldots]($ Ob. Cit. p. 59)

En el párrafo que antecede, no se evidencia las leyes morales como; ama suwa ${ }^{12}$, ama kella ${ }^{13}$, ama llullla ${ }^{14}$, etc. Que algunos autores contemporáneos de tendencia histórica lo asignan a los Inca runas, muchas veces se ha ensañado durante nuestra formación básica en el curso de Historia del Perú, el tema acerca de las leyes morales de los Incas, siempre inician la sesión resaltando las cuatro leyes morales. Por lo menos, tal cosa, no se evidencia en la concepción de Guaman Poma de Ayala, es decir, lo que manifiesta el autor es que los Inca runas durante el proceso de su desarrollo no se mataban ni se robaban. Tampoco existían hombres perezosos. En tal sentido cabe sostener que no se evidencia otras cosas que se hace notar como leyes morales de los inca runas, si esto es así, los argumentos que nos han ido proponiendo en los colegios no sería de todo verdadero. Las leyes morales que algunos autores asignan están más bien relacionado con las expresiones y acciones negativas de manera absoluta, estas supuestas leyes están más bien relacionadas con el contenido bíblico, además el término ama en el idioma kechwa es poco usual, por no decir nada usual entre los runas, lo que se suele emplear en las diferentes conversaciones es el término mana, debemos explicitar que en la expresión de los runas indígenas tales prohibiciones absolutas no solían darse. Los runas solían usar el término allin o allinta el cual se traduce como "bien o hacer el bien", dichos términos indican acción de hacer el bien o de hacer bien lo que se pretende, de este modo, es poco frecuente que alguien diga mana y el término ama esta fuera del contexto.

Para complementar lo que se ha expuesto conviene notar lo siguiente:

[...]: ves aquí en toda la ley cristiana no he hallado que sean tan codiciosos en oro ni plata los indios, ni he hallado quien deba cien pesos, ni mentiroso, ni jugador, ni perezoso, ni puta ni puto, ni quitarse entre ellos, que vosotros lo tenéis todo, inobedientes a vuestro padre y madre y prelado y rey; [...] (Guaman Poma, 1993, p. 277)

\footnotetext{
12 No seas ladrón.

${ }^{13}$ No seas ocioso.

${ }^{14}$ No seas mentiroso.
} 
Este manifiesto es crucial para sintetizar la situación de los Inca runas en lo que respecta a las buenos modales y la práctica de lo justo, por lo menos, frente a la actitud de los invasores, entonces cabe preguntarnos ¿Quiénes son los ladrones, perezosos y mentirosos?, si quisiéramos responder a esta pregunta, todo apunta que tales cosas practicaron los invasores bajo los lemas de que su misión era la evangelización.

La segunda perspectiva del autor es dar cuenta del mal trato que sufrieron los antiguos runas de esta tierra. La pretensión del autor es que se tenga en cuenta el modo de vida y las formas de sentir de los runas como diferentes al de España, para ello deberían tener en cuenta la formación de las sociedades y que la vivencia de estas sociedades obedece a la práctica tradicional de sus costumbres.

[...]: Que un español gentil tenía su ídolo de plata, que él lo había labrado con sus manos, y otro español había hurtado; de ello fue llorando a buscar su ídolo, más lloraba del ídolo que de la plata. Así los indios, como bárbaros y gentiles, lloraban de sus ídolos cuando se los quebraron en tiempo de la conquista.[...] (Guaman Poma, 1993, p. 278)

El sentir de los invasores obedecen a la cuestión material y nada relacionado con la misión de la evangelización, en ese sentido es evidente la observación del autor en cuanto refiere que el español llora por su ídolo, puesto que aquello había sido labrado por él. En el caso de los indígenas, el dolor es más fuerte, puesto que son arrebatados sus ídolos con el fundamento de que aquellos runas eran bárbaros por ende idólatras. Finalmente, cabe señalar que en nuestros tiempos aún estos problemas que ha sido revelado por el autor no han sido superados por la élite criolla de nuestros tiempos, aunque sin ser criollos pretenden serlo. Por otra parte, el indígena de nuestros tiempos muchas veces está dudando de su capacidad y muchas veces al llegar a la capital empiezan a imitar y pretenden aparentar lo que no verdaderamente son, bajo la mirada del autor cada individuo debe tener las agallas para enfrentar las situaciones adversas, a su vez cabe recordar que cada individuo es un ser único y como ente único hay mucho por hacer. También cabe resaltar que muchos indígenas de nuestros tiempos están reivindicando lo que se ha ido perdiendo durante el proceso del desarrollo histórico, tal es el caso de los individuos de la región Arequipa que han ido resistiendo frente a la invasión de las empresas mineras autorizados por el gobierno peruano. Lo mismo ocurre con individuos de la zona amazónica, quienes constantemente han ido poniendo su voz de protesta en contra de las empresas mineras, además de las prácticas ilegales de la explotación minera. Los hombres de estas comunidades han dado cuenta de que estos hechos están generando consecuencia irreversibles en lo que respecta al hombre, naturaleza, animales y otros seres que los habitan.

\section{CONCLUSIONES}

La carta de don Martín Guaman Mallqi, tiene la finalidad de dar cuenta acerca del servicio que prestó a la corona española, por lo que solicita el reconociendo de su hijo y nietos como príncipes y que se le asigne la facultad de ser rey para ejercer con autonomía el cargo de gobernador en estas tierras, en el escrito insiste que ellos serían las personas idóneas para ejercer los cargos. 
En la parte introductoria de su obra, Murúa describe su asombro ante el orden, organización y la finura que muestra las construcciones de los diversos templos construidos por los runas de la sociedad Inca, además de la sociedad Yucatán en México.

En la carta emitida por Guaman Poma de Ayala, se pueda notar claramente la actitud temeraria que muestra ante la corona Española. También es evidente, el atrevimiento el cual es aprovechado para describir el pasado, relatar el presente, predecir el futuro, además de proponer ciertas alternativas de solución a fin de salvaguardar el caos en estas tierras.

Guaman Poma de Ayala utiliza el término filósofo para designar a los sabios de la sociedad Inca, a fin de comunicar al rey y a los lectores cristianos que en estas tierra existían tales hombres de gran sabiduría y su función era la de comprender generalmente el comportamiento astronómico, para luego comunicar al rey y a sus representantes.

La obra del autor inicia con la descripción del origen de los runas y en cada una de estas generaciones resalta las leyes y su praxis, las mismas que habrían mantenido de generación en generación, teniendo como reflejo y modelo a los miembros de la familia, en términos generales el respeto entre los runas y el cuidado del otro prima por encima de todas las cosas.

Guaman Poma de Ayala, para mantener el orden dentro de esta sociedad solicita que se le conceda como súbdito de la corona española, a fin de solucionar la situación crítica por lo que atravesaban los runas de la sociedad incaica y si no fuera así, el mismo rey Felipe III de España debe asumir la gobernabilidad en esta tierra. Con la aplicación de una de estas alternativas se podría frenar el caos que se había suscitado de manera radical.

En los párrafos finales se hace un breve análisis de la situación actual por la que estamos atravesando como sociedad, las quejas están latentes por los individuos de las diferentes regiones del interior de nuestro país y el rechazo a los representantes del Congreso de la República va tomando eco cada día, puesto que la mayoría de los congresistas no han asumido su función que le compete.

\section{REFERENCIAS BIBLIOGRÁFICAS}

Adorno, R. (1989). Cronista y principe la obra de don Felipe Guaman Poma de Ayala. Lima. PUCP.

Guaman Poma, F. ([1615]1993). Nueva crónica y buen gobierno (Tomos; I y II). México: Fondo de Cultura Económica.

Molina, C. (2008). Ritos y fábulas de los incas. Lima: Universidad de San Martín de Porres.

Murúa, F. (2001). Historia general del Perú. Madrid: DASTIN.

Santa Cruz, J. (1993). Relación de antigüedades deste reyno del Piru (Estudio Etnohistórico y Lingüístico de Pierre Duviols y César Itier). Cusco: IFEA-CBC 